\title{
Tuberculosis in children: New diagnostic blood tests
}

\author{
F Kakkar, UD Allen, D Ling, M Pai, IC Kitai; Canadian Paediatric Society, \\ Infectious Diseases and Immunization Committee
}

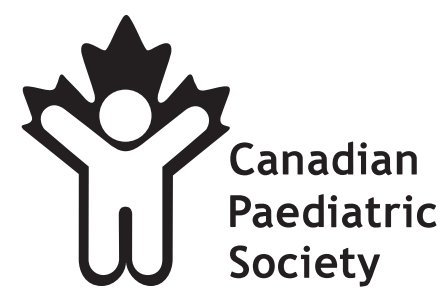

\begin{abstract}
F Kakkar, UD Allen, D Ling, M Pai, IC Kitai; Canadian Paediatric Society, Infectious Diseases and Immunization Committee. Tuberculosis in children: New diagnostic blood tests. Can J Infect Dis Med Microbiol 2010;21(4):e111-e115.

The interferon-gamma-release assays were developed to overcome the pitfalls and logistic difficulties of the tuberculin skin test (TST) for the diagnosis of latent tuberculosis infection (LTBI). These blood tests measure the in vitro production of interferon-gamma by sensitized lymphocytes in response to Mycobacterium tuberculosis-specific antigens. Two interferon-gamma-release assays are registered for use in Canada: the QuantiFERON-TB Gold In-Tube assay (Cellestis Inc, Australia) and the T.SPOT-TB test (Oxford Immunotec, United Kingdom). Evaluation of these tests has been hampered by the lack of a gold standard for LTBI, and limited paediatric data on their use. It appears that they are more specific than the TST, and may be useful for evaluating TST-positive patients at low risk of true LTBI. Moreover, they may add sensitivity if used in addition to the TST in immunocompromised patients, very young children and close contacts of infectious adults. A summary of these tests, their limitations and their application to clinical paediatric practice are described.
\end{abstract}

F Kakkar, UD Allen, D Ling, M Pai, IC Kitai; Société canadienne de pédiatrie, comité des maladies infectieuses et d'immunisation. La tuberculose chez les enfants : de nouvelles analyses sanguines diagnostiques

Les tests de détection de l'interféron gamma ont été mis au point pour vaincre les écueils et les problèmes logistiques liés à l'intradermoréaction à la tuberculine (IDR) afin de diagnostiquer la tuberculose-infection latente (TBIL). Ces analyses sanguines mesurent la production in vitro d'interféron gamma par des lymphocytes sensibilisés en réponse aux antigènes spécifiques de Mycobacterium tuberculosis. Deux tests de détection de l'interféron gamma sont homologués au Canada : le test QuantiFERON-TB Gold In-Tube (Cellestis Inc., Australie) et le test T.SPOT-TB (Oxford Immunotec, Royaume-Uni). Leur évaluation a été gênée par l'absence de norme de référence de la TBIL et par le peu de données pédiatriques quant à leur usage. Il semble qu'ils soient plus précis que l'IDR et qu'ils puissent être utiles pour évaluer les patients positifs à l'IDR peu vulnérables à une véritable TBIL. De plus, ils pourraient être plus sensibles s'ils s'ajoutent à l'IDR chez les patients immunocompromis, les très jeunes enfants et les contacts étroits d'adultes infectieux. Un sommaire de ces tests, leurs limites et leur application à la pratique clinique en pédiatrie sont présentés.

Key Words: Diagnosis; Interferon-gamma-release assay; Paediatrics; Tuberculosis

Cor centuries, paediatric tuberculosis (TB) has been a Challenge for physicians to diagnose and treat (1-3). Unlike TB in adults, paediatric TB often presents with nonspecific signs and symptoms. Paediatric TB is usually paucibacillary, and culture confirmation is difficult and not always possible (4-6). At the same time, the diagnosis of latent TB infection (LTBI), while extremely important in paediatrics, can be challenging due to the limitations in the sensitivity and specificity of the only available screening test to date - the tuberculin skin test (TST) (7). The test is supported by longitudinal data showing a much higher risk of TB disease in TST-positive individuals. The latter individuals experience a beneficial effect of isoniazid prophylaxis (8). Current recommendations advocate targeted testing of children at high risk for TB infection or progression of LTBI to TB disease (Refer to Table 1 for testing recommendations) (9). However, the TST has poor sensitivity (leading to false negatives) in very young children, infants younger than three months of age and immunocompromised patients $(1,10)$. It can be influenced by many factors such as malnutrition, concurrent viral and parasitic infections, and concurrent medical conditions and diseases (11). It is also known to have poor sensitivity in active and/or disseminated TB infection (7). The TST also suffers from poor specificity (leading to false-positive tests) in certain uninfected individuals who have been previously vaccinated with Bacillus Calmette-Guérin (BCG) or infected with environmental nontuberculous mycobacteria (NTM). The test is further hampered by poor standardization, inter- and intraobserver variability, and the need for a return visit for interpretation.

\section{ADVANCES IN TB DIAGNOSIS: THE INTERFERON-GAMMA-RELEASE ASSAYS} These tests measure the in vitro production of interferongamma by sensitized lymphocytes in response to Mycobacterium

Correspondence: Canadian Paediatric Society, 2305 St Laurent Boulevard, Ottawa, Ontario K1G 4J8. Telephone 613-526-9397,

fax 613-526-3332, e-mail info@cps.ca, websites www.cps.ca, www.caringforkids.cps.ca 


\section{TABLE 1}

\section{Targeted tuberculosis (TB) screening: Indications for the tuberculin skin test in children}

Contacts of known cases of active TB

Children with suspected active TB disease

Children with known risk factors for progression of infection to disease

Children travelling or residing for three months or longer in an area with a high incidence of TB, especially if the visit is anticipated to involve contact with the local population

Children who arrived in Canada from countries with a high TB incidence within the previous two years

Adapted from reference 9

\section{TABLE 2}

Interferon-gamma-release assays

The QuantiFERON-TB Gold In-Tube assay (Cellestis Inc, Australia)

What it measures

Whole blood ELISA, which measures the interferon-gamma concentration in blood after incubation with the tuberculosis-specific antigens ESAT-6, CFP-10 and TB7.7. Response to both mitogen stimulation and a control are also measured to ensure quality of the assay

Specimen and processing requirements Requires the collection of $3 \mathrm{~mL}$ of blood, $1 \mathrm{~mL}$ per tube (antigen, mitogen, nil). Samples must be processed within $12 \mathrm{~h}$ of collection. These tubes are incubated for $16 \mathrm{~h}$ to $24 \mathrm{~h}$, after which time the amount of interferon-gamma produced is measured via ELISA

Interpretation of results Results are reported as either positive (measured interferon-gamma $0.35 \mathrm{IU} / \mathrm{mL}$ or greater, and greater than $50 \%$ above the control), negative (measured interferon-gamma $0.35 \mathrm{IU} / \mathrm{mL}$ or less) or indeterminate (measured interferon-gamma less than $0.35 \mathrm{IU} / \mathrm{mL}$ and suboptimal mitogen response of less than $0.5 \mathrm{lU} / \mathrm{mL}$, or measured interferon-gamma of $0.7 \mathrm{IU} / \mathrm{mL}$ or less above the control/nil response)

The T.SPOT-TB test (Oxford Immunotec, United Kingdom) What it measures Ex-vivo enzyme-linked immunoassay, which estimates the number of T cells producing interferon-gamma after exposure to Mycobacterium tuberculosis-specific antigens. Isolated peripheral blood mononuclear cells from the patient are placed into microlitre wells, panel A (ESAT-6), panel B (CFP-10), nil control or mitogen, and then incubated to allow stimulation of any sensitized $T$ cells present. The number of $T$ cells producing interferon-gamma are then counted and quantified

Specimen and processing requirements The T.SPOT-TB assay requires $8 \mathrm{~mL}$ of blood for children older than 10 years of age, $4 \mathrm{~mL}$ for children between two and 10 years of age, and $2 \mathrm{~mL}$ for children younger than two years of age (with double the volume requirement for immunocompromised patients). Samples must be processed on the same day (within $8 \mathrm{~h}$ of collection)

Interpretation of results Results are presented as the number of spot-forming T cells (SFCs), and classified as either positive, negative, borderline or indeterminate. A result is defined as positive when either panel A or B contains eight or more SPCs more than the negative control, negative when both panel A or B contains four or less SPCs than the negative control, and borderline, when the highest of panel A or B contains five, six, or seven SPCs more than the negative control. A borderline test is considered equivocal and should be repeated

The presence of a satisfactory reaction (greater than 20 SFCs) to the mitogen-positive control demonstrates $T$ cell function and validates the assay result. An indeterminate result is reported when high background levels prevent interpretation (greater than 10 SFCs in nil/control wells), or when less than 20 SFC are detected in the mitogen-positive control wells

Adapted from references 15 and 16

tuberculosis-specific antigens. The genes encoding these antigens are present in $M$ tuberculosis, but are not found in any BCG strain or in several of environmental NTM strains $(12-14)$. Therefore, these tests are substantially more specific (leading to fewer false positives) than the TST. They are also less subjective with respect to interpretation, have the potential for rapid turnaround time, and require only a single visit to complete the testing process. Two commercial interferon-gamma-release assays (IGRAs) using these $M$ tuberculosis-specific antigens are now currently registered for use in Canada - the QuantiFERON-TB Gold In-Tube assay (QFT-G-IT; Cellestis Inc, Australia) and the T.SPOT-TB test (Oxford Immunotec, United Kingdom).
Brief descriptions of the tests are presented in Table 2. They are not yet widely available at most centres or reference laboratories in Canada. Both tests are also approved by the United States Food and Drug Administration $(15,16)$. The ELISpot, while similar to the T.SPOT, is an in-house assay not available for commercial use, although it is frequently referenced in studies of the IGRAs.

\section{ROLE OF THE IGRAS IN CHILDREN: WHEN SHOULD THEY BE USED?}

While the IGRAs have been well studied in adults and reviewed elsewhere (17), data regarding their use in children are much more limited. Current recommendations for their use 
in children are best understood in the context of this limited available information. In summary, in low TB incidence settings, there is general support that the tests are more specific and correlate better with gradients of exposure to infectious source cases than the TST (18-21). However, evaluation of this is hampered by the lack of a gold standard test for the diagnosis of LTBI, and the lack of longitudinal data to validate the predictive value of the IGRAs compared with the TST. Overall agreement between the TST and the IGRA in the diagnosis of LTBI in children appears to be between 55\% and 95\% $(18-20,22,23)$, and varies depending on age and history of previous $B C G$ vaccination (24). The majority of discordant results are $\mathrm{TST}^{+} / \mathrm{IGRA}^{-}$, and there is concern that the IGRAs may not be as sensitive as the TST for the diagnosis of LTBI in very young and immunocompromised children, and whether the initial infection was remote $(24,25)$. The 2009 American Academy of Pediatrics Red Book recommendations on TB states that "IGRAs cannot be recommended routinely for use in children younger than 5 years of age or for immunocompromised children of any age because of a lack of published data about their utility with these groups (26)". While there are limited data to suggest that the IGRAs, especially the T.SPOT, may have increased sensitivity over the TST in immunocompromised populations, this again has not been well studied in children and is based on a limited number of adult studies (17). However, the T.SPOT is more difficult to perform, more expensive and requires larger volumes of blood than the QFT-G-IT.

There is also variable sensitivity reported in children with active tuberculosis disease, ranging from 50\% to $92 \%$ for QFT-G-IT, $81 \%$ to $93 \%$ for ELISpot, and $40 \%$ to $83 \%$ for T.SPOT-TB (18-20,27-29). The wide range in reported sensitivity appears to reflect the different performances of these tests across different ages and in different settings (endemic versus nonendemic). In very young children with $\mathrm{TB}$, the test may have limited sensitivity, but there are notable cases on record in which the TST is negative and the IGRA is positive (29). The combination of the two tests may, therefore, increase sensitivity for the diagnosis of $\mathrm{TB}$, both latent and active, in situations in which the TST may be unreliable such as in active and or disseminated TB disease, and in latent disease of very young infants and immunocompromised patients.

Acknowledging these limitations, recommendations on IGRAs for latent TB infection were made by the Canadian Tuberculosis Committee in 2007 and updated in 2008 and 2010 (30-32). Members of the Infectious Diseases and Immunization Committee of the Canadian Paediatric Society reviewed and agreed with the 2008 updated guidelines, which include specific recommendations for the use of the IGRAs for children, as described below.

\section{CANADIAN TB COMMITTEE RECOMMENDATIONS ON THE USE OF IGRAS FOR CHILDREN:}

- The IGRAs may be used as a supplementary diagnostic aid in combination with the TST to help support the diagnosis of active TB.
In the absence of a positive TST or culture confirmation, a positive IGRA could potentially support the diagnosis of TB based on typical clinical, radiological or other laboratory findings. However, the IGRA must never be used in isolation to make a diagnosis of TB disease. Every effort must still be made to obtain a microbiological confirmation of active TB. A negative IGRA test (or TST) does not rule out active TB at all ages, but especially in young children.

- The IGRAs may be used in the setting of contact investigation to confirm a positive TST in contacts who, on the basis of an assessment of the duration and degree of contact with an active infectious case, are believed to have a low pretest probability of recently acquired LTBI, and who have no other high or increased risk factors for progression to active disease if infected.

This can be especially useful in the school outbreak setting, in which the population to be screened for contact tracing may be low risk, and yet have falsepositive TSTs from BCG or NTM. However, for close contacts of the index case, or those contacts who have high or increased risk of progression to active disease if infected, a TST (or both TST and IGRA) should be used eight to 12 weeks from the most recent exposure and, if either is positive, the contact should be considered to have LTBI. If both TST and IGRA testing are used, blood should be drawn for IGRA on or before the day when the TST is read.

- The IGRAs may be performed in a TST-positive, immunocompetent child with relatively low risk of being infected with $\mathrm{TB}$, and of progressing to active disease if infected. Persons with a positive IGRA result may be considered for treatment of LTBI.

This recommendation allows the physician to order an IGRA when she/he suspects a false-positive TST result in a child or adolescent who has a low risk probability of LTBI and no risk factors for progression to active disease. For example, this may apply to low-risk children for whom a TST is performed for school or volunteer requirements. In these instances, the IGRA may be useful to confirm diagnosis of LTBI for treatment purposes. Any decision not to offer chemoprophylaxis on the basis of a negative IGRA must be made in consultation with a TB specialist.

- Routine or mass screening of all immigrant children for LTBI, with either TST or IGRA, is not recommended. However, targeted screening for LTBI after arrival in Canada is recommended for foreign-born children and travellers with risk factors for reactivation of LTBI.

Immigrant children who should be targeted for LTBI screening include those younger than 15 years of age who have lived in a country with high TB incidence and have immigrated within the past two years, and children with risk factors for progression to disease, as outlined in Table 3. 
TABLE 3

Risk factors for the development of active tuberculosis (TB) among persons infected with Mycobacterium tuberculosis

\begin{tabular}{lc}
\hline Risk factor & Estimated risk of TB relative to persons with no known risk factor \\
\hline High risk & $110-170$ \\
AIDS & $50-110$ \\
HIV infection & $20-74$ \\
Transplantation (related to immunosuppressive therapy) & 30 \\
Silicosis & $10-15$ \\
Chronic renal failure requiring hemodialysis & 16 \\
Carcinoma of head and neck & $15-19$ \\
Recent TB infection (two years or less) & 4.9 \\
Abnormal chest x-ray - fibronodular disease & $1.5-4$ \\
Increased risk & $2.0-3.6$ \\
Treatment with glucocorticoids & $2-3$ \\
Tumour necrosis factor-alpha inhibitors & $2.2-5.0$ \\
Diabetes mellitus (all types) & $2-3$ \\
Underweight (90\% or lower of ideal body weight; for most persons, this & 2 \\
corresponds to a body mass index of $20 \mathrm{~kg} / \mathrm{m}^{2}$ or lower) & 2 \\
Young age when infected (zero to four years of age) & 1 \\
Cigarette smoker (one pack/day) & 16 \\
Abnormal chest x-ray - granuloma & \\
Low risk & \\
Infected person, no known risk factor, normal chest x-ray (low risk reactor) & \\
\hline Adapted from reference 9. Reproduced with the permission from the Minister of Public Works and Government Services Canada, 2010
\end{tabular}

Adapted from reference 9. Reproduced with the permission from the Minister of Public Works and Government Services Canada, 2010

- The IGRAs can be used, in addition to the TST, to diagnose LTBI infection in an immunocompromised patient.

In an immunocompromised child, the TST should still be the initial test used to detect LTBI. If the TST is positive, the child should be considered to have LTBI. However, given the known problem with false-negative TST results in immunocompromised populations, a physician still concerned about the possibility of LTBI in an immunocompromised child with a negative initial TST result may perform an IGRA test.

ACKNOWLEDGEMENTS: The principal authors thank Daphne Ling and Madhukar Pai for their assistance during the development of this document.

\section{REFERENCES}

1. Newton SM, Brent AJ, Anderson S, Whittaker E, Kampmann B. Paediatric tuberculosis. Lancet Infect Dis 2008;8:498-510.

2. Shingadia D, Novelli V. Diagnosis and treatment of tuberculosis in children. Lancet Infect Dis 2003;3:624-32.

3. Marais BJ, Pai M. Recent advances in the diagnosis of childhood tuberculosis. Arch Dis Child 2007;92:446-52.

4. Marais BJ, Gie RP, Schaaf HS, Beyers N, Donald PR, Starke JR. Childhood pulmonary tuberculosis: Old wisdom and new challenges. Am J Respir Crit Care Med 2006;173:1078-90.

5. Hesseling AC, Schaaf HS, Gie RP, Starke JR, Beyers N. A critical review of diagnostic approaches used in the diagnosis of childhood tuberculosis. Int J Tuberc Lung Dis 2002;6:1038-45.

6. Donald PR. Childhood tuberculosis: Out of control? Curr Opin Pulm Med 2002;8:178-82.

7. Huebner RE, Schein MF, Bass JB Jr. The tuberculin skin test. Clin Inf Dis 1993;17:968-75.

8. Ferebee SH. Controlled chemoprophylaxis trials in tuberculosis. A general review. Bibl Tuberc 1970;26:28-106.

9. Public Health Agency of Canada. Canadian Tuberculosis Standards. <http://www.phac-aspc.gc.ca/tbpc-latb/pubs/tbstand07-eng.php> (Accessed on September 15, 2010).

10. Madhi SA, Gray GE, Huebner RE, Sherman G, McKinnon D, Pettifor JM. Correlation between CD4+ lymphocyte counts, concurrent antigen skin test, and tuberculin skin test reactivity in human immunodeficiency virus type 1 -infected and -uninfected children with tuberculosis. Pediatr Infect Dis J 1999;18:800-5.

11. Andersen P, Munk ME, Pollock JM, Doherty TM. Specific immunebased diagnosis of tuberculosis. Lancet 2000;356:1099-104.

12. Fine PE, Sterne JA, Pönnighaus JM, Rees RJ. Delayed-type hypersensitivity, mycobacterial vaccines and protective immunity. Lancet 1994;344:1245-9.

13. Berthet FX, Rasmussen PB, Rosenkrands I, Andersen P, Gicquel B. A Mycobacterium tuberculosis operon encoding ESAT-6 and a novel low-molecular-mass culture filtrate protein (CFP-10). Microbiology 1998;144:3195-203.

14. Pai M, Dheda K, Cunningham J, Scano F, O’Brien R. T-cell assays for the diagnosis of latent tuberculosis infection: Moving the research agenda forward. Lancet Infect Dis 2007;7:428-38.

15. QuantiFERON-TB-Gold In-Tube: Technical information. $<$ www.cellestis.com/IRM/content/aust/qtfproducts_tbgoldintube techinfo.html $>$ (Accessed on September 15, 2010).

16. T.SPOT-TB. 8-well strip plate format (TB.300). Package insert for Canada. <www.oxfordimmunotec.com/CANpageinsert> (Accessed on September 15, 2010).

17. Pai M, Zwerling A, Menzies D. Systematic review: T-cell-based assays for the diagnosis of latent tuberculosis infection: An update. Ann Intern Med 2008;149:177-84.

18. Detjen AK, Keil T, Roll S, et al. Interferon-gamma release assays improve the diagnosis of tuberculosis and nontuberculous mycobacterial disease in children in a country with a low incidence of tuberculosis. Clin Infect Dis 2007;45:322-8.

19. Dogra S, Narang P, Mendiratta DK, et al. Comparison of a whole blood interferon-gamma assay with tuberculin skin testing for the detection of tuberculosis infection in hospitalized children in rural India. J Infect 2007;54:267-76.

20. Okada K, Mao TE, Mori T, et al. Perfomance of an interferon-gamma release assay for diagnosing latent tuberculosis infection in children. Epidemiol Infect 2008;136:1179-87.

21. Soysal A, Millington KA, Bakir M, et al. Effect of BCG vaccination on risk of Mycobacterium tuberculosis infection in children with household tuberculosis contact: A prospective community-based study. Lancet 2005;366:1433-51. 
22. Tsiouris SJ, Austin J, Toro P, et al. Results of a tuberculosis-specific IFN-gamma assay in children at high risk for tuberculosis infection. Int J Tuberc Lung Dis 2006;10:939-41.

23. Lighter J, Rigaud M, Eduardo R, Peng CH, Pollack H. Latent tuberculosis diagnosis in children by using the QuantiFERON-TB Gold In-Tube test. Pediatrics 2009;123:30-7.

24. Bakir M, Millington KA, Soysal A, et al. Prognostic value of a T-cell-based, interferon-gamma biomarker in children with tuberculosis contact. Ann Intern Med 2008;149:777-87.

25. Farhat M, Greenaway C, Pai M, Menzies D. False-positive tuberculin skin tests: What is the absolute effect of BCG and non-tuberculous mycobacteria? Int J Tuberc Lung Dis 2006;10:1192-204.

26. American Academy of Pediatrics. Red Book: 2009 Report of the Committee on Infectious Diseases. <http://aapredbook. aappublications.org/current.dtl> (Accessed on September 15, 2010).

27. Liebeschuetz S, Bamber S, Ewer K, Deeks J, Pathan AA, Lalvani A. Diagnosis of tuberculosis in South African children with a T-cell-based assay: A prospective cohort study. Lancet 2004;364:2196-203.
28. Higuchi K, Harada N, Mori T, Sekiya Y. Use of QuantiFERON-TB Gold to investigate tuberculosis contacts in a high school. Respirology 2007;12:88-92.

29. Nicol MP, Davies MA, Wood K, et al. Comparison of T-SPOT.TB assay and tuberculin skin test for the evaluation of young children at high risk for tuberculosis in a community setting. Pediatrics 2009; 123:38-43.

30. Canadian Tuberculosis Committee. Interferon gamma release assays for latent tuberculosis infection. An Advisory Committee Statement (ACS). Can Commun Dis Rep 2007;33:1-18.

31. Canadian Tuberculosis Committee. Updated recommendations on interferon gamma release assays for latent tuberculosis infection. An Advisory Committee Statement (ACS). Can Commun Dis Rep 2008;34:1-13.

32. Canadian Tuberculosis Committee. Recommendations on interferon gamma release assays for the diagnosis of latent tuberculosis infection - 2010 update. An Advisory Committee Statement (ACS). Can Commun Dis Rep 2010;36:ACS-5:1-13.

\section{INFECTIOUS DISEASES AND IMMUNIZATION COMMITTEE (2009-2010)}

Members: Drs Robert Bortolussi, IWK Health Centre, Halifax, Nova Scotia (Chair); Jane Finlay, Richmond, British Columbia; Jane C McDonald, The Montreal Children's Hospital, Montreal, Quebec; Heather Onyett, Kingston General Hospital, Kingston, Ontario; Joan L Robinson, Edmonton, Alberta; Élisabeth Rousseau-Harsany, Sainte-Justine UHC, Montreal, Quebec (Board Representative)

Liaisons: Drs Upton D Allen, The Hospital for Sick Children, Toronto, Ontario (Canadian Pediatric AIDS Research Group); Charles PS Hui, Children's Hospital of Eastern Ontario, Ottawa, Ontario (CPS Liaison to Health Canada, Committee to Advise on Tropical Medicine and Travel); Nicole Le Saux, Children's Hospital of Eastern Ontario, Ottawa, Ontario (Immunization Program, ACTive); Larry Pickering, Elk Grove, Illinois, USA (American Academy of Pediatrics); Marina I Salvadori, Children's Hospital of Western Ontario, Ottawa, Ontario (CPS Liaison to Health Canada, National Advisory Committee on Immunization)

Consultants: Drs James Kellner, Calgary, Alberta; Ian C Kitai, The Hospital for Sick Children, Toronto, Ontario, Noni E MacDonald, IWK Health Centre, Halifax, Nova Scotia; Dorothy L Moore, The Montreal Children's Hospital, Montreal, Quebec

Principal authors: Ms Fatima Kakkar, Drs Upton Allen and Ian C Kitai, The Hospital for Sick Children, Toronto, Ontario

The recommendations in this statement do not indicate an exclusive course of treatment or procedure to be followed. Variations, taking into account individual circumstances, may be appropriate. All Canadian Paediatric Society position statements and practice points are reviewed, revised or retired as needed on a regular basis. Please consult the "Position Statements" section of the CPS website (www.cps.ca/ english/publications/statementsindex.htm) for the most current version. This article also appears in the October 2010 issue of Paediatrics $\mathbb{E}$ Child Health. 


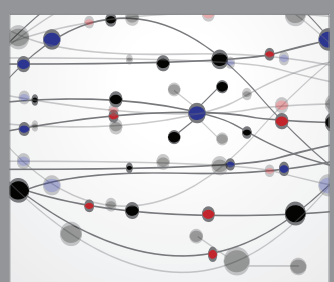

The Scientific World Journal
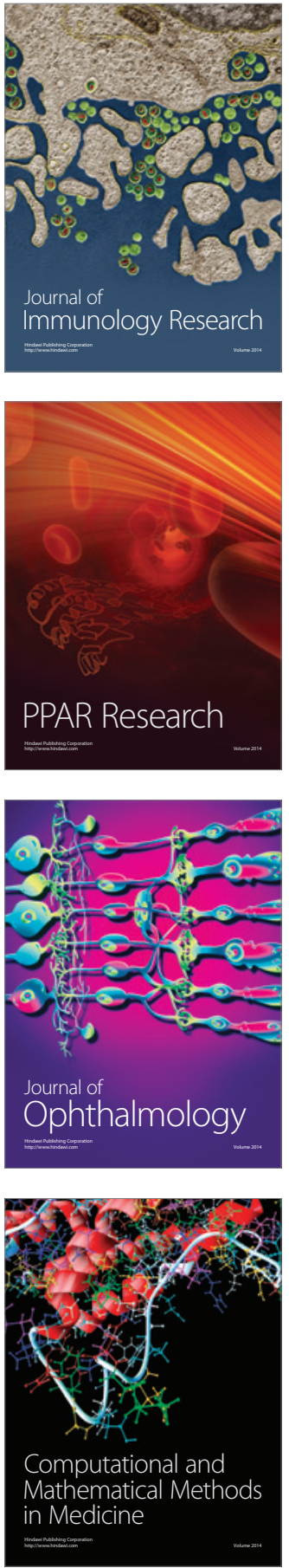

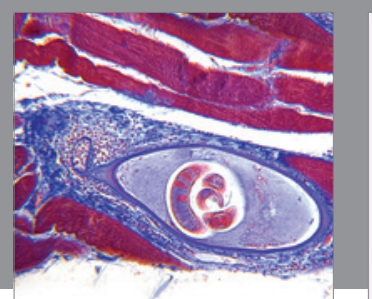

Gastroenterology Research and Practice

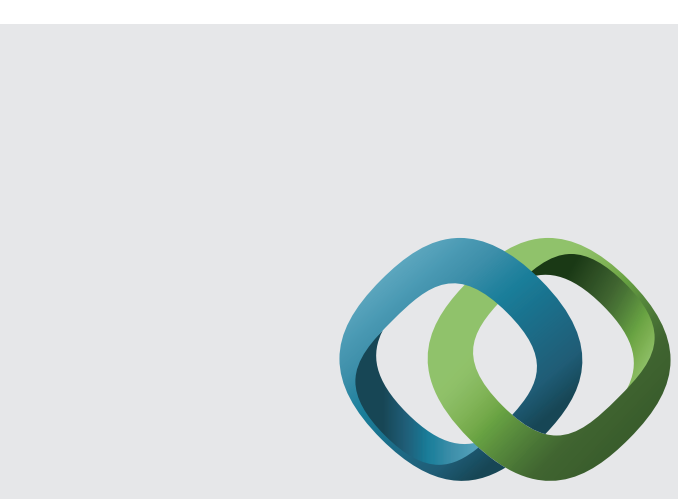

\section{Hindawi}

Submit your manuscripts at

http://www.hindawi.com
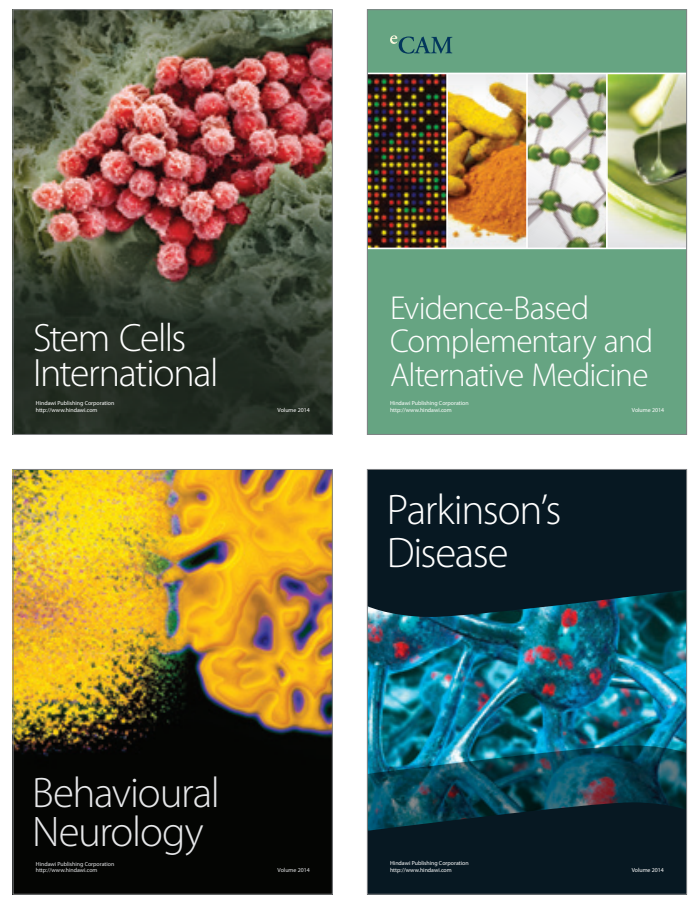
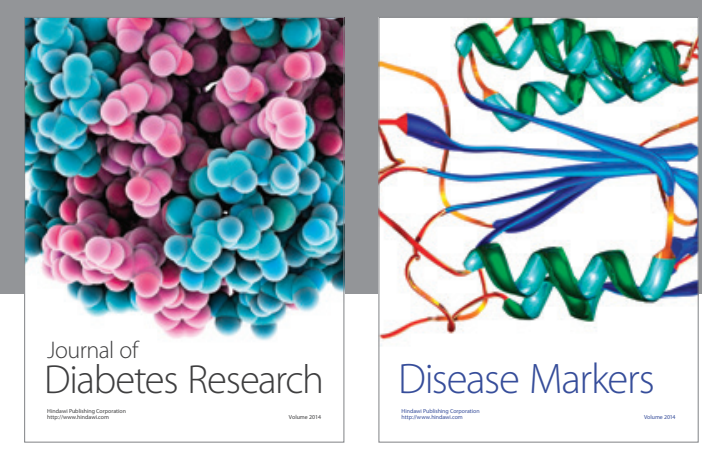

Disease Markers
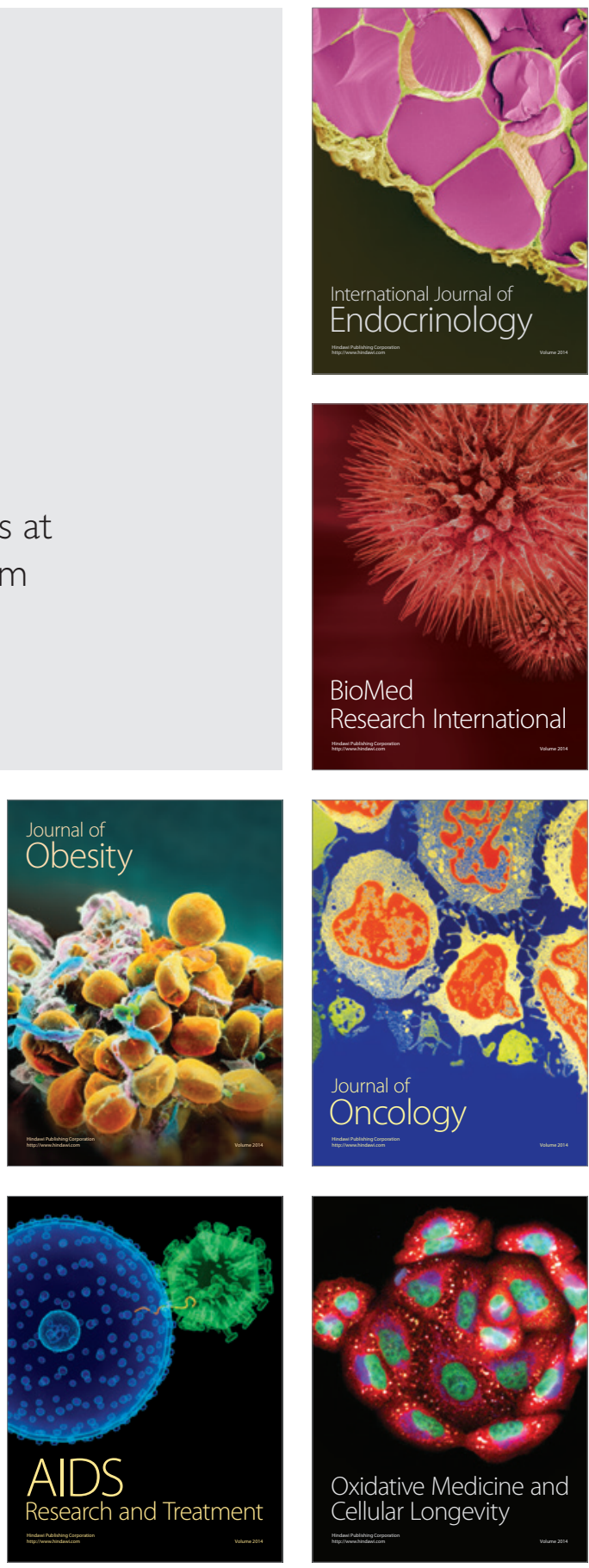